\title{
Drospirenone-containing oral contraceptives and venous thromboembolism: an analysis of the FAERS database
}

This article was published in the following Dove Press journal:

Open Access Journal of Contraception

\section{David Madigan \\ Jennifer Shin}

Department of Statistics, Columbia University, New York, NY, USA
Correspondence: David Madigan

Columbia University, 208 Low Library,

MC 4314, 535 West I I6th Street, New

York, NY 10027, USA

$\mathrm{Tel}+\mathrm{I} 2128548296$

Fax + I 2128545401

Email david.madigan@columbia.edu
Introduction: Substantial evidence suggests that drospirenone-containing oral contraceptives may cause a higher risk of venous thrombotic events than earlier-generation oral contraceptives. Methods: To gain insight into recent real-world implications, we conducted an analysis using the US Food and Drug Administration's Adverse Event Reporting System.

Results: Venous thrombotic events continue to be reported at a much higher rate with drospirenone-containing oral contraceptives than the general background. The disproportionality has been rising since 2010. The same behavior is not seen with levonorgestrel-containing oral contraceptives. Conclusion: Our results are consistent with decreased physician and patient awareness of risks associated with drospirenone-containing oral contraceptives.

Keywords: drug safety, Yaz, venous thrombotic events, FDA adverse event reporting system, disproportionality

\section{Introduction}

Oral contraceptives are among the most widely used drugs ${ }^{1}$ and questions about oral contraceptive safety have occupied regulators, physicians, and patients for decades. Venous thrombotic risks associated with oral contraceptives have attracted particular scrutiny. A substantial body of evidence linked the first generation of oral contraceptive pills (OCPs) to significant risk of venous thromboembolism (VTE). The estrogen-like compounds in these OCPs appeared to be the cause. Subsequently, drug developers decreased the VTE risk of OCPs by lowering the delivered estrogen content by adding progestins such as levonorgestrel. ${ }^{2}$ More recently, OCPs with the progestin drospirenone (Yaz/Yasmin) have enjoyed considerable commercial success, in part by emphasizing potential benefits such as reduced acne.,

Evidence began to emerge in the 2000s, however, that drospirenone-containing OCPs may cause higher risk of VTE than earlier generation OCPs. Recent systematic reviews show elevated risk, ${ }^{5,6}$ but others emphasize the modest absolute risk: "Regardless of whether the thrombotic risk of drospirenone OCs compared to levonorgestrel OCs is increased by 1.5 -fold or threefold, the absolute risk is still low." ${ }^{7}$

The US Food and Drug Administration's Adverse Event Reporting System (FAERS) database contains voluntarily submitted adverse event reports. The data can be downloaded from the FDA's website (http://bit.ly/2naXeJU). To shed light on real-world experience with drospirenone OCPs and using standard analytical techniques, we considered reporting of VTE associated with drospirenone OCPs as compared with the rest of the drugs in FAERS and also considered reporting of VTE associated with 
levonorgestrel OCPs as compared with the rest of the drugs in the database.

\section{Methods}

For each year since the introduction of drospirenonecontaining OCPs, we compared the cumulative reporting of VTE events in the FAERS database associated with these OCPs with the general background using a standard measure of disproportionality. We conducted a similar analysis for levonorgestrel-containing OCPs. Because this study involved analysis of publicly available deidentified data, no Institutional Board Approval was required.

\section{Identification of VTE events}

Our analysis uses the Standardized MedDRA Query (SMQ) "Embolic and Thrombotic Events, Venous." Table 1 provides the included MedDRA preferred terms. SMQs are groupings of MedDRA preferred terms that relate to a defined medical condition or area of interest. The included terms may relate to signs, symptoms, diagnoses, syndromes, physical findings, laboratory, and other physiologic test data, etc, related to the medical condition or area of interest. SMQs were developed to facilitate retrieval of MedDRA-coded data as a first step in investigating drug safety issues in pharmacovigilance and clinical development. Below, we refer to the "Embolic and Thrombotic Events, Venous" SMQ endpoint as "Venous Thrombotic (SMQ)."

\section{Inclusion criteria for oral contraceptives}

The medical literature concerning epidemiological studies of oral contraceptives frequently groups oral contraceptives according to progestin (eg, Dinger et $\mathrm{al}^{8}$ or Jick et $\mathrm{al}^{9}$ ). In our analysis, we considered two progrestins: drospirenone and levonorgestrel. We included products that were listed on the investigational new drug application for each of these progestins and that have oral contraception as an indication. Table 2 lists the specific products that we included.

\section{Disproportionality metric}

We used the lower bound of a $90 \%$ interval for the "information component (IC)" statistic. ${ }^{10}$ This statistic is commonly referred to as IC05. Because it is the lower end of the interval, IC05 is always closer to one than the IC and is thus more conservative than IC. The IC05 calculations stratify by age, sex, and year of report.

In practice, disproportionality metrics are often used with "signal thresholds" that dictate whether or not a given drug-outcome pair generates a signal. For example,
Table I MedDRA terms included in the SMQ Embolic and Thrombotic Events, Venous

\begin{tabular}{|c|c|}
\hline \multicolumn{2}{|c|}{ Venous thrombotic (SMQ) preferred terms } \\
\hline $\begin{array}{l}\text { Axillary vein thrombosis } \\
\text { Budd-Chiari syndrome }\end{array}$ & $\begin{array}{l}\text { Pulmonary thrombosis } \\
\text { Pulmonary vein occlusion }\end{array}$ \\
\hline Catheterization venous & Pulmonary veno-occlusive disease \\
\hline Cavernous sinus thrombosis & Pulmonary venous thrombosis \\
\hline Central venous catheterization & Renal vein embolism \\
\hline Cerebral venous thrombosis & Renal vein occlusion \\
\hline $\begin{array}{l}\text { Compression stockings } \\
\text { application }\end{array}$ & Renal vein thrombosis \\
\hline Deep vein thrombosis & Retinal vein occlusion \\
\hline $\begin{array}{l}\text { Deep vein thrombosis } \\
\text { postoperative }\end{array}$ & Retinal vein thrombosis \\
\hline Embolism venous & SI QIII TIII pattern \\
\hline Hepatic vein occlusion & Splenic vein occlusion \\
\hline Hepatic vein thrombosis & Splenic vein thrombosis \\
\hline Homans' sign positive & Subclavian vein thrombosis \\
\hline Iliac vein occlusion & Superior sagittal sinus thrombosis \\
\hline Inferior vena cava syndrome & Superior vena cava syndrome \\
\hline Inferior vena caval occlusion & Thrombophlebitis \\
\hline $\begin{array}{l}\text { Intracranial venous sinus } \\
\text { thrombosis }\end{array}$ & Thrombophlebitis migrans \\
\hline $\begin{array}{l}\text { Intravenous catheter } \\
\text { management }\end{array}$ & Thrombophlebitis neonatal \\
\hline Jugular vein thrombosis & Thrombosed varicose vein \\
\hline May-Thurner syndrome & Thrombosis corpora cavernosa \\
\hline Mesenteric vein thrombosis & Transverse sinus thrombosis \\
\hline Obstetrical pulmonary embolism & Vascular graft \\
\hline Paget-Schroetter syndrome & Vena cava embolism \\
\hline Pelvic venous thrombosis & Vena cava filter insertion \\
\hline Penile vein thrombosis & Vena cava thrombosis \\
\hline Phlebectomy & Venogram abnormal \\
\hline Phleboplasty & Venoocclusive disease \\
\hline Portal vein occlusion & Venoocclusive liver disease \\
\hline Portal vein thrombosis & Venous occlusion \\
\hline $\begin{array}{l}\text { Postprocedural pulmonary } \\
\text { embolism }\end{array}$ & Venous operation \\
\hline Postthrombotic syndrome & Venous recanalisation \\
\hline Postoperative thrombosis & Venous stent insertion \\
\hline Postpartum venous thrombosis & Venous thrombosis \\
\hline Pulmonary embolism & Venous thrombosis in pregnancy \\
\hline Pulmonary infarction & Venous thrombosis limb \\
\hline Pulmonary microemboli & Venous thrombosis neonatal \\
\hline
\end{tabular}

Abbreviation: SMQ, Standardized MedDRA Query.

Szarfman et al ${ }^{11}$ proposed using a threshold of 2 for the "EB05" measure, quantitatively very similar to the IC05. ${ }^{11}$ We indicate this threshold in Figure 1.

The IC and IC05 are used by the World Health Organization for safety assessment in its program for International Drug Monitoring. ${ }^{10,12}$

\section{Results}

A signal of disproportionate reporting for drospirenonecontaining OCPs appeared in 2002, well before any epidemio- 
logical studies raised any concerns, and persists to this day. It is unclear why the IC05 declined in the 2005-2010 period (albeit remaining well above the standard signaling threshold of 2), but it has increased steadily since then and is currently above 11 . The IC05 for drospirenone-containing OCPs is approximately five times higher than that for levonorgestrel-containing OCPs.

Figure 1 shows the IC05 values for each quarter from the first quarter of 2000 through the first quarter of 2016.

Table 2 Specific drugs included

\begin{tabular}{ll}
\hline Progestin & Products \\
\hline Drospirenone & Drospirenone and Ethinyl Estradiol \\
Yasmin & Yaz \\
Ocella & Alesse \\
Levonorgestrel & Aviane \\
Enpresse & Lessina \\
Levlite \\
Levora \\
Loseasonique \\
Low-ogestrel \\
Lybrel \\
Nordette \\
Portia \\
Seasonale \\
Seasonique \\
Triphasil \\
Trivora \\
\hline
\end{tabular}

\section{Discussion}

Spontaneous report databases remain a mainstay of modern pharmacoepidemiology. Lester et $\mathrm{al}^{13}$ provide a recent demonstration of the importance of spontaneous report analyses in characterizing drug safety issues. The article considered all drug label changes in 2010 and reported that "Spontaneous reports were the most common evidence source from which drug safety issues were identified that resulted in safety-related label changes in 2010 when analyzed both by unique safety issue and drug (52\% and $55 \%$ of all evidence sources, respectively)." Moore et al ${ }^{14}$ conducted a similar exercise, in their case looking at 2009 label changes involving major regulatory safety actions. The authors state that spontaneous reports "formed the basis of 77 of 135 new regulatory actions (57\%) and 19 of 25 new boxed warnings (76\%)." Hennessy and Strom ${ }^{15}$ state: "Spontaneous reporting systems remain to this day a crucial means of uncovering important postapproval drug safety information."

Spontaneous report data have some inherent, welldocumented limitations relying as they do on voluntary reporting. Underreporting is a particular concern that has been well documented and, furthermore, the data provide limited temporal information to inform analyses. ${ }^{16}$ Some authors refer to the possibility of "stimulated" or publicitytriggered reporting to FAERS. A recent comprehensive review of FDA safety alerts suggests modest evidence for

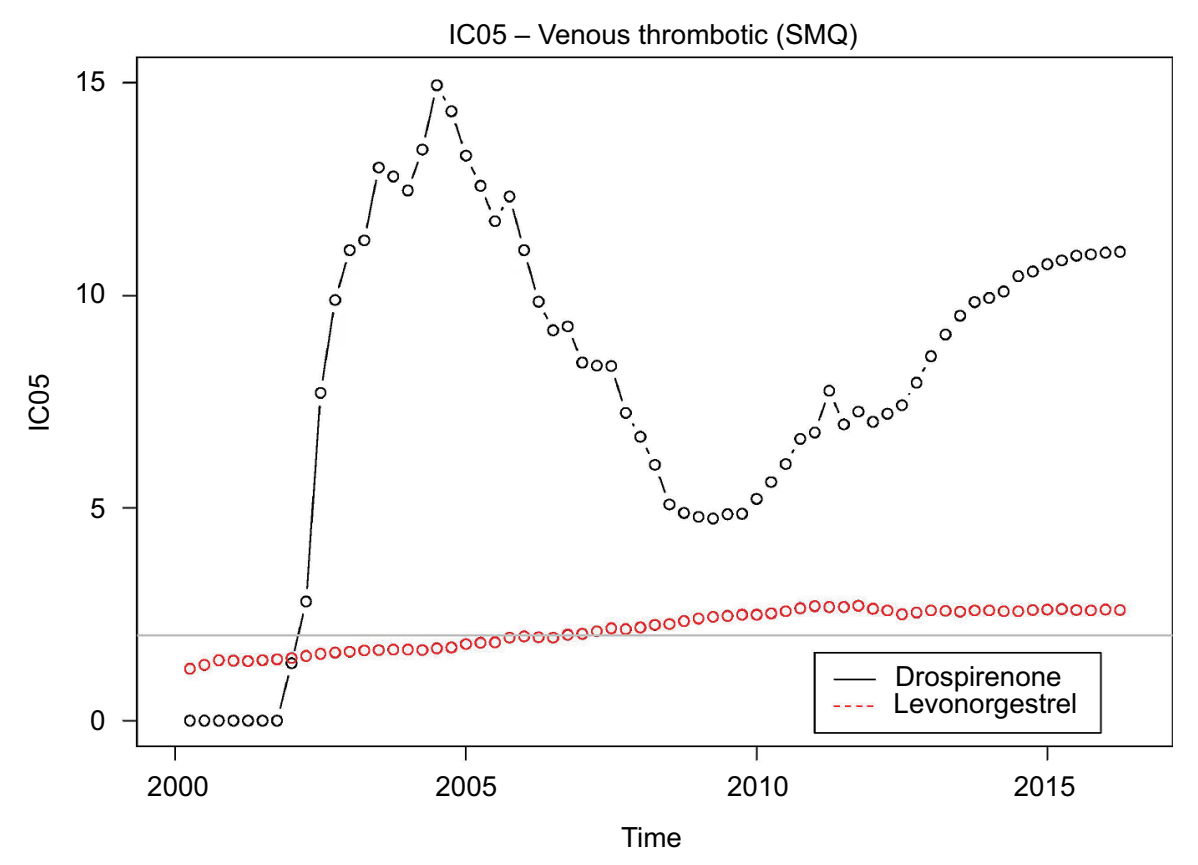

Figure I IC05 values for drospirenone-containing OCPs and levonorgestrel-containing OCPs.

Abbreviations: OCP, oral contraceptive pills; SMQ, Standardized MedDRA Query. 
significant reporting changes associated with the issuance of alerts. ${ }^{17}$ Some earlier studies drew similar conclusions. ${ }^{18,19}$ Disproportionality analyses provide limited opportunity for adjustment for potential confounding and this possibility cannot be ruled out.

\section{Conclusion}

Our analysis suggests that drospirenone-containing OCPs may result in many more VTEs than levonorgestrel-containing OCPs and that the gap is widening in recent years.

\section{Disclosure}

Dr Madigan testified for plaintiffs in litigation related to Yaz in 2011. The authors report no other conflicts of interest in this work.

\section{References}

1. IMS Institute for Healthcare Informatics. Medicine use and spending shifts: a review of the use of medicines in the United States in 2014. Parsippany, NJ: IMS Institute for Healthcare Informatics; 2015.

2. Manzoli L, De Vito C, Marzuillo C, Boccia A, Villari P. Oral contraceptives and venous thromboembolism. Drug Saf. 2012;35(3):191-205.

3. The Food and Drug Administration. Yaz: Warning Letter. Silver Spring, MD: The Food and Drug Administration; 2008. Available from: http:// bit.ly/2FjVSbP. Accessed March 08, 2018.

4. Geampana A. Pregnancy is more dangerous than the pill: a critical analysis of professional responses to the Yaz/Yasmin controversy. Social Sci Med. 2016;166:9-16.

5. Wu CQ, Grandi SM, Filion KB, Abenhaim HA, Joseph L, Eisenberg MJ. Drospirenone-containing oral contraceptive pills and the risk of venous and arterial thrombosis: a systematic review. BJOG. 2013;120(7):801-811.

6. de Bastos M, Stegeman BH, Rosendaal FR, et al. Combined oral contraceptives: venous thrombosis. Cochrane Database Syst Rev. 2014;(3):CD010813.
7. Jick SS. Drospirenone-containing oral contraceptives may increase the risk of venous thromboembolism. Evid Based Nurs. 2014;17(3):71.

8. Dinger JC, Heinemann LAJ, Kuhl-Habich D. The safety of a drospirenone-containing oral contraceptive: final results from the European Active Surveillance study on Oral Contraceptives based on 142,475 women-years of observation. Contraception. 2007;75(5): 344-354.

9. Jick H, Jick SS, Myers MW, Vasilakis C, Gurewich V. Risk of idiopathic cardiovascular death and nonfatal venous thromboembolism in women using oral contraceptives with differing progestagen components. Lancet. 2005;346:1589-1593.

10. Noren GN, Hopstadius J, Bate A. Shrinkage observed-to-expected ratios for robust and transparent large-scale pattern discovery. Stat Methods Med Res. 2013;22(1):57-69.

11. Szarfman A, Machado SG, O'Neill RT. Use of screening algorithms and computer systems to efficiently signal higher-than-expected combinations of drugs and events in the US FDA's spontaneous reports database. Drug Saf. 2002;25(6):381-392.

12. Hopstadius J, Norén GN, Bate A, Edwards IR. Impact of stratification on adverse drug reaction surveillance. Drug Saf. 2008;31(11): $1035-1048$.

13. Lester J, Neyarapally GA, Lipowski E, Graham CF, Hall M, Dal Pan G. Evaluation of FDA safety - related drug label changes in 2010. Pharmacoepidemiol Drug Saf. 2013;22(3):302-305.

14. Moore TJ, Singh S, Furberg CD. The FDA and new safety warnings. Arch Int Med. 2012;172(1):78-80.

15. Hennessy S, Strom BL. Improving postapproval drug safety surveillance: getting better information sooner. Ann Rev Pharmacol Toxicol. 2015;55: $75-87$.

16. Hazell L, Shakir SA. Under-reporting of adverse drug reactions: a systematic review. Drug Saf. 2006;29:385-396.

17. Hoffman KB, Demakas AR, Dimbil M, Tatonetti NP, Erdman CB. Stimulated reporting: the impact of US Food and Drug Administrationissued alerts on the Adverse Event Reporting System (FAERS). Drug Saf. 2014;37(11):971-980.

18. van Hunsel F, van Puijenbroek E, de Jong-van den Berg L, van Grootheest $\mathrm{K}$. Media attention and the influence on the reporting odds ratio in disproportionality analysis: an example of patient reporting of statins. Pharmacoepidemiol Drug Saf. 2010;19(1):26-32.

19. Moore TJ, Cohen MR, Furberg CD. Serious adverse drug events reported to the Food and Drug Administration, 1998-2005. Arch Int Med. 2007;167(16):1752-1759.
Open Access Journal of Contraception

\section{Publish your work in this journal}

Open Access Journal of Contraception is an international, peerreviewed, open access, online journal, publishing original research, reports, reviews and commentaries on all areas of contraception. In addition to clinical research, demographics and health-related aspects, the journal welcomes new findings in animal and preclinical studies

\section{Dovepress}

relating to understanding the biological mechanisms and practical development of new contraceptive agents. The manuscript management system is completely online and includes a very quick and fair peer-review system. Visit http://www.dovepress.com/testimonials.php to read real quotes from published authors. 